\title{
Perspectivas de licenciandos em Física sobre a Educação de Jovens e Adultos
}

\author{
Larissa Carniel da Silva*, Patrícia Ignácio**, Tobias Espinosa ${ }^{\star \star *}$
}

\section{Resumo}

O presente estudo buscou compreender quais são os entendimentos sobre o conceito, os sujeitos, o ensino e a aprendizagem na Educação de Jovens e Adultos (EJA), de licenciandos de um curso de licenciatura com habilitação em Física de uma universidade pública federal localizada na Região Metropolitana de Porto Alegre. Para isso, utilizou-se de entrevistas gravadas em áudio, posteriormente, analisadas sob o olhar da Análise Temática, descrita por Braun e Clarke (2006). De acordo com as análises realizadas, os achados da pesquisa mostraram que os licenciandos: pouco sabem o que é a EJA; percebem os alunos da EJA como um público diversificado; entendem que os alunos desta modalidade não possuem interesse pelos estudos; acreditam que os alunos da EJA aprendem de forma lenta e dificultosa; mencionam a importância da realização de sondagem junto aos alunos, para o planejamento da aula; apostam, preferencialmente, em metodologias tradicionais, sugerindo, também, metodologias ativas e a mescla dessas. Por fim, os resultados apontam a necessidade de repensar os currículos dos cursos de licenciatura em Física e de um maior investimento em pesquisas sobre o Ensino de Física na EJA.

Palavras-chave: Educação de Jovens e Adultos, Ensino de Física, Formação de professores de Física, Ensino e Aprendizagem na EJA, Análise Temática.

- Mestranda em Ensino de Ciências Exatas pela Universidade Federal do Rio Grande (FURG). Licenciada em Ciências Exatas também pela FURG. Contato: larissacarniel@furg.br

* Doutora em Educação pela Universidade Federal de Pernambuco (UFPE), Mestre em Educação pela Universidade Luterana do Brasil (ULBRA) e Licenciada em Pedagogia pela Universidade do Vale do Rio dos Sinos (UNISINOS). Contato: patricia.ignacio@furg.br

*** Doutor em Ensino de Física pela Universidade Federal do Rio Grande do Sul (UFRGS). Mestre em Ensino de Física também pela UFRGS. Licenciado em Física pela Universidade do Vale do Rio dos Sinos (UNISINOS). Contato: tobiasespinosa@furg.br

Recebido em: 07/04/2020; Aceito em: 29/01/2021

https://doi.org/10.5335/rbecm.v4i2.10817

http://creativecommons.org/licenses/by-nc-nd/4.0

ISSN: 2595-7376 


\section{Introdução}

O Ensino de Física para jovens e adultos se constitui em uma das habilitações do curso de Licenciatura em Física ${ }^{1}$. Contudo, a partir de uma primeira inserção em uma turma da Educação de Jovens e Adultos (EJA), vivenciada por parte dos autores deste artigo na disciplina de Estágio I, no último ano em um curso de licenciatura com habilitação em Física, pôde-se perceber o quanto as turmas da EJA possuem características diferenciadas em relação ao ensino regular e entre si. Com isso, o presente estudo teve por interesse entender como ocorre a formação de professores nessa modalidade de ensino. Isso porque, ao se deparar com a ação docente perante uma turma de EJA, os autores em questão notaram a falta de conhecimentos sobre o fazer docente em relação ao funcionamento, ao planejamento, às metodologias e às avaliações específicas para essa modalidade de ensino nos licenciandos da referida disciplina. A questão que reverbera das vivências descritas retoma a fragilidade da formação dos cursos de licenciatura quanto às diferenças que demarcam a Educação de Jovens e Adultos e como trabalhar com esta modalidade.

A Educação de Jovens e Adultos é uma modalidade educacional criada com o objetivo de possibilitar às pessoas que não tiveram acesso à escola na idade convencional concluir seus estudos nos ensinos fundamental e médio (BRASIL, 2000). Pensando particularmente no Ensino de Física na EJA, investigou-se como tem sido a formação de professores na área, se os futuros professores saem da licenciatura preparados para trabalhar e quais seus entendimentos sobre essa modalidade de ensino.

Em relação à estrutura curricular dos cursos de formação de professores para o ensino de Física, o Parecer 1304/2001² aponta que os cursos de licenciatura em Física devem conter aproximadamente $50 \%$ da carga horária total composta de disciplinas como: Física Geral, Matemática, Física Moderna e Contemporânea e disciplinas complementares. Esse documento ainda afirma que, para a licenciatura em Física, serão incluídos, no conjunto dos conteúdos profissionais, os conteúdos da Educação Básica, considerando as Diretrizes Curriculares Nacionais para a Formação de Professores em Nível Superior (BRASIL, 2015), bem como as Diretrizes Nacionais para a Educação Básica (BRASIL, 2013). O documento das Diretrizes Curriculares Nacionais para a Formação de Professores em Nível Superior define que 
[...] para a Formação Inicial e Continuada em Nível Superior de Profissionais do Magistério para a Educação Básica aplicam-se à formação de professores para o exercício da docência na educação infantil, no ensino fundamental, no ensino médio e nas respectivas modalidades de educação (Educação de Jovens e Adultos, Educação Especial, Educação Profissional e Tecnológica, Educação do Campo, Educação Escolar Indígena, Educação a Distância e Educação Escolar Quilombola), nas diferentes áreas do conhecimento e com integração entre elas, podendo abranger um campo específico e/ou interdisciplinar (BRASIL, 2015, p. 3).

Assim, o que se percebe é uma perspectiva de formação ampla, onde o objetivo é habilitar os futuros professores para a Educação Básica em todas as suas modalidades. Isso faz com que se reflita sobre a forma como se dá essa formação, tendo em vista a diversidade de realidades nas quais o professor de Física pode se inserir.

Posto isto, a pergunta de pesquisa que norteou o presente artigo foi: Quais são os entendimentos de licenciandos em Física de um curso de licenciatura com habilitação em Física de uma universidade pública federal da Região Metropolitana de Porto Alegre acerca do conceito, dos sujeitos, do ensino e da aprendizagem na EJA?

Para tanto, desenvolveu-se uma pesquisa qualitativa, na qual foram realizadas entrevistas individuais semiestruturadas ${ }^{3}$ a fim de investigar quais os entendimentos de 12 licenciandos em Física sobre o conceito, os sujeitos, o ensino e a aprendizagem na EJA, em um curso de licenciatura com habilitação em Física. As entrevistas foram gravadas em áudio e, posteriormente, analisadas sob o olhar da Análise Temática descrita por Braun e Clarke (2006).

\section{A educação de jovens e adultos no brasil}

A Lei de Diretrizes e Bases da Educação (LDB) nº 9.394/1996 especifica que a EJA é uma modalidade de ensino cujo objetivo é possibilitar às pessoas que, por algum motivo, não concluíram a educação básica durante a infância e adolescência, voltem a estudar. A LDB (1996), no inciso VII art. 4º ainda afirma que o dever do Estado com a educação escolar pública será efetivado mediante a garantia de: "oferta de educação escolar regular para jovens e adultos, com características e modalidades adequadas às suas necessidades e disponibilidades, garantindo-se aos que forem trabalhadores as condições de acesso e permanência na escola".

O papel da EJA no Parecer 11/20004, segundo Soares (2002, p. 13), é estabelecer: 
a 'função reparadora', que se refere ao ingresso no circuito dos direitos civis, pela restauração de um direito negado; a 'função equalizadora', que propõe garantir uma redistribuição e alocação em vista de mais igualdade de modo a proporcionar maiores oportunidades, de acesso e permanência na escola, aos que até então foram mais desfavorecidos; por último, a função, por excelência da EJA, permanente, descrita no documento como a 'função qualificadora'. É a função que corresponde às necessidades de atualização e de aprendizagem contínuas, próprias da era em que nos encontramos.

Com isso, a EJA deixa de ter função de suprir, compensar a escolaridade perdida, como na legislação anterior, e foca nas novas funções descritas pelo Parecer 11/2000.

A EJA pode ser ofertada nas seguintes modalidades: Proeja, Encceja e EJA a distância. O Proeja se constitui no ensino da EJA oferecido junto com um curso técnico de formação profissional ou vice-versa. O termo é encontrado com mais frequência nos Institutos Federais de Educação Tecnológica do Governo Federal (DECRETO nº 5.8405 , 2006). O Encceja, segundo o Ministério da Educação (2018), é o Exame Nacional para Certificação de Competências de Jovens e Adultos, que visa a conclusão do Ensino Básico, através de exames, incluindo a certificação de pessoas que moram no exterior e a população carcerária. Já a modalidade de EJA a distância, segundo o Parecer 6/2010 (2010), surgiu como uma oportunidade para os jovens e adultos concluírem o ensino básico. No Parecer 6/2010 (2010, p. 22) é destacada a necessidade de se desenvolver estudos sobre a relação entre a EJA e a EaD (Educação a Distância) "para obterem maior compreensão das reais possibilidades da Educação a Distância em EJA”. Segundo Fajardo (2018), os estados, os quais são responsáveis pela formação dos currículos, precisam da aprovação dos conselhos locais para a adesão da EJA a distância, o que pode ocorrer ainda este ano. Segundo o Parecer 11/2000 (2000, p. 39), a idade mínima para ingresso em cursos da EJA no ensino fundamental "que também objetivem exames supletivos desta etapa, só pode ser superior a 14 anos completos dado que 15 anos completos é a idade mínima para inclusão em exames supletivos" e o "estudante da EJA de ensino médio deve ter mais de 17 anos completos para iniciar um curso da EJA. E só com 18 anos completos ele poderá ser incluído em exames" (BRASIL, 2000, p. 40).

Sobre o ensino nessa modalidade, o PNE (Plano Nacional de Educação) de 2001, na seção 5.1, declara que "é necessária [...] a produção de materiais didáticos e técnicas pedagógicas apropriadas, além da especialização do corpo docente”, tendo em vista as suas especificidades. Além disso, a meta 11 da seção 5.1 do PNE de 2001 assinalava a relevância de 
estimular a concessão de créditos curriculares aos estudantes de educação superior e de cursos de formação de professores em nível médio que participarem de programas de educação de jovens e adultos.

Isso mostra que, no PNE de 2001, havia interesse no fornecimento de material específico à EJA, na formação continuada de professores dessa modalidade e também na inserção do assunto nas ementas das disciplinas dos cursos de licenciaturas no país.

Entretanto, no PNE de 2014 a concessão de créditos curriculares aos estudantes de graduação, não permaneceu. Já, o estímulo à formação continuada de professores para trabalhar com a EJA, continuou. Com isso, compreende-se que ao mesmo tempo em que há avanços nas legislações sobre a EJA, ainda há um longo caminho a se percorrer em relação à formação de professores para essa modalidade de ensino.

\section{Quem são os sujeitos frequentadores da EJA}

Sabe-se que a EJA é destinada a jovens e adultos que não tiveram acesso à escola na idade adequada, mas quem são eles, especificamente? Segundo o Censo Escolar de 2018 (INEP, 2019), cerca de 52\% dos alunos matriculados na EJA possuem idades de 15 a 24 anos. Isso mostra que, atualmente, os frequentadores da EJA são em sua maioria jovens.

Os dados do Censo Escolar de 2018 (INEP, 2019) ainda mostram que, 52\% dos frequentadores da EJA são homens, e os outros $48 \%$ são mulheres. Além disso, $39,09 \%$ são pardos, $16,05 \%$ brancos, $5,58 \%$ pretos, $0,75 \%$ indígenas, $0,35 \%$ amarelos e $38,18 \%$ não é declarado.

Loch (2009) relata, através de sua experiência docente na EJA, que o público da EJA poderá ser um morador de rua, um jovem deficiente, um adulto trabalhador, avós de 70, 80 anos, negros, brancos, pardos, homossexuais etc.

Ao encontro disso, Haddad e Di Pierro (2000) explicam que, o grupo social constituído por jovens passou a ser maior número, na Educação de Jovens e Adultos, a partir dos anos 80, e que possui uma trajetória escolar anterior mal sucedida. Em relação à presença de jovens na EJA, Brunel (2008, p. 9) explica em seu livro que

os jovens, quando chegam nesta modalidade, em geral, estão desmotivados, desencantados com a escola regular, com histórico de repetência de um, dois, três anos ou mais. Muitos deles sentem-se perdidos no contexto atual, principalmente em relação ao emprego e à importância do estudo para a sua vida e inserção no mercado de trabalho. 
Em experiência com a EJA, vivenciada por parte dos autores deste artigo, pode-se observar o elevado número de jovens advindos do ensino regular, nessa modalidade. Esses alunos, geralmente, foram excluídos do ensino regular por não avançarem ou por mau comportamento.

De acordo com Souza (2012, p. 15), os frequentadores da EJA "são pessoas que possuem trajetória de vida marcada por exclusão, perdas e esperanças”. Ou seja, são pessoas que, em alguns casos, já internalizaram a incapacidade de aprender. Por isso, o educador da EJA deve ser capaz de reacender nessas pessoas a crença na sua potencialidade em aprender.

Sobre os sujeitos frequentadores da EJA, Lise e Andreolla (2014) realizaram um estudo cujo objetivo era identificar o novo ${ }^{7}$ sujeito dessa modalidade na Escola Básica Municipal Rui Barbosa, da cidade de Chapecó. Para isso, os autores desenvolveram um levantamento sobre a faixa etária dos alunos e realizaram perguntas tais como: "Você trabalha?"; "Qual é o seu horário de trabalho?"; "Como você se considera quanto a sua cor?"; e "Quantas pessoas da sua casa estudam, excluindo você?”. Os resultados apontaram que, cerca de 39\% tinham idades de 15 a 20 anos, $74 \%$ eram trabalhadores, $63 \%$ trabalhavam em horário comercial, $40 \%$ se consideravam brancos, $38 \%$ se consideravam pardos e $39 \%$ não possuíam nenhum membro da família que estudasse. Para os autores, a divulgação desses dados para a escola possibilitaria que a mesma soubesse "quem é realmente esse 'novo' [...] sujeito, os seus problemas, seus anseios, suas necessidades, suas facilidades” para assim, se adequar para melhor receber esse aluno (LISE; ANDREOLLA, 2014, p. 72).

Em relação ao educando adulto, Pinto (2010, p. 86) diz que ele

é antes de tudo um membro 'atuante' da sociedade. Não apenas por ser um trabalhador, e sim pelo conjunto de ações que exerce sobre um círculo de existência. $\mathrm{O}$ adulto analfabeto é um elemento frequentemente de alta influência na comunidade.

Isso remete ao entendimento de que o adulto analfabeto, apesar de não possuir um conhecimento considerado válido pela escola, possui um conjunto de conhecimentos importantes para seus pares e parece se mostrar influente em sua comunidade.

Por fim, foi possível verificar que o público da EJA é diversificado e, também, diferente dos alunos regulares. Isso mostra a necessidade de uma formação específica ao professor (e futuro professor) dessa modalidade de ensino. 


\section{Formação de professores para a EJA}

Em se tratando da formação de professores para jovens e adultos, Arroyo (2006, p. 17) expressa que "a formação do educador e da educadora de jovens e adultos sempre foi um pouco pelas bordas, nas próprias fronteiras onde estava acontecendo a EJA". Segundo o autor, a causa disso é o fato de não se ter parâmetros oficiais que delineiam o perfil e a formação do educador dessa modalidade porque, também, não se tem uma definição ainda muito clara da própria EJA. Além disso, segundo Arroyo (2006, p. 18), a EJA

é uma área que permanece em construção, em uma constante interrogação. Um aspecto que talvez tenha sido muito bom para a própria EJA é o fato de ela não ter conseguido nunca, ou nem sequer tentado, conformar-se no sistema educacional. Isso fez com que não se tentasse também conformar a formação do educador e da educadora da EJA num marco definido.

Para Lise e Andreolla (2014, p. 59), "um dos maiores problemas da EJA no momento atual é a falta de professores com formação específica na área para atender a esse público diferenciado, de forma significativa e enriquecedora". Ao encontro disso, Machado (2008, p. 165) menciona que a formação de um profissional preparado para trabalhar com jovens e adultos é importante e que essa deveria ser tratada na formação inicial desses professores, pois

a maioria dos cursos de formação de professores nos prepara para atuar com o aluno ideal - por que não dizer irreal. Aprendemos os conteúdos de nossas áreas, conhecemos algumas ferramentas pedagógicas e metodológicas, mas estamos longe de pensar a realidade concreta da escola na qual iremos atuar, ao assumir um contrato temporário ou, mesmo, ao passar num concurso para cargos efetivos nas redes públicas de ensino. É a primeira questão a ser enfrentada pela formação de professores da EJA: há que se repensar os currículos dos cursos de licenciatura, para que a formação inicial trate dessa modalidade de ensino.

Percebendo o distanciamento entre a formação de professores e a realidade da EJA, neste trabalho, considera-se a formação do educador da EJA de suma importância para uma potencial qualificação e aprimoramento nos processos de ensino e na aprendizagem dos alunos. Ou seja, a formação de um professor de Física que possua formação para a EJA, e outras modalidades, é extremamente necessária nos dias atuais.

Em meio a esse debate, Ventura e Bomfim (2015) realizaram um estudo com o objetivo de contribuir para a discussão sobre o lugar que a EJA ocupa na formação 
inicial de professores, promovida nos cursos de licenciatura. Ao investigar como a formação do professor da EJA aparece em documentos oficiais, os autores concluíram que a EJA é "alvo de metas modestas, políticas descontinuadas e fragmentadas, iniciativas focais e aligeiradas, [...] no qual a universalização da educação básica de qualidade para todos vem sendo assunto menor" (VENTURA; BOMFIM, 2015, p. 211).

No que se refere ao educador de adultos, Pinto (2010, p. 85-86) fala que se deve "considerar o educando não como um ser marginalizado, um caso de anomalia social, mas, ao contrário, como um produto normal da sociedade em que vive”. Além disso, o educador ainda precisa

considerar o educando como um ser 'pensante'. É um portador de ideias e um produtor de ideias, dotado frequentemente de alta capacidade intelectual, que se revela espontaneamente em sua conversação, em sua crítica aos fatos, em sua literatura oral. O que ocorre é que em presença do erudito arrogante, 'culto' (o 'doutor') o analfabeto se sente inferiorizado e seu comportamento se torna retraído (PINTO, 2010, p. 86).

Dizendo de outro modo, é preciso ver seu aluno como um universo de possibilidades, um sujeito escolar capaz como todos os outros, um ser pensante e com uma caminhada de inserção social, ao longo de toda a sua vida.

Ainda sobre a presença da EJA nas licenciaturas, Koch (2014) realizou uma pesquisa com o objetivo de analisar a existência de elementos formativos relacionados à EJA, desenvolvidos nos cursos de uma instituição de ensino superior da Região de Chapecó. Com a análise das matrizes curriculares, observou que, dos 13 cursos de licenciaturas dessa instituição, 10 deles ofereciam de um a quatro créditos voltados à EJA. A partir da perspectiva da autora, concluiu-se que a formação para a docência na EJA mostra muitas lacunas na formação inicial e continuada dos educadores e que se deve cada vez mais discutir sobre a EJA nas licenciaturas.

Segundo Loch (2009), o educador deve sempre considerar que para elaborar o planejamento e a avaliação na EJA se deve pensar: com os educandos, a sua vida, as suas necessidades, os seus desejos e as suas aspirações articulados com a realidade social e cultural em que vivem, num processo conjunto em que o ver, o ouvir e o agir estão conectados. Assim sendo, percebe-se uma enorme tendência, entre os estudiosos, em considerar os saberes e experiências do educando como parte fundamental nos processos de ensino e de aprendizagem.

Em relação a isso, Giovanetti (2007, p. 247) busca ressaltar a extrema importância do olhar diferente que o educador da EJA precisa ter em relação aos seus alunos 
ao reeducarmos o nosso olhar docente, à luz do legado da educação popular, poderemos superar a negatividade ainda tão presente em nossas abordagens sobre os alunos da EJA, ainda referidos por meio de uma visão marcada pela "carência", o que acaba por reafirmar uma postura preconceituosa e estigmatizada.

Isso porque, a EJA é um campo da educação que se dedica a seres humanos marcados pela exclusão social, advindos das camadas populares. E, por isso, o educador precisa reconstruir o seu olhar a respeito desses educandos. Com isso, compreende-se o quão a formação de professores voltada para a EJA é importante e necessária nos cursos de licenciaturas.

\section{Ensino de Física na EJA}

Para um breve levantamento acerca das pesquisas sobre o Ensino de Física na EJA no Brasil, realizou-se buscas nas plataformas Scielo (Scientific Electronic Library Online) e BDTD (Biblioteca Digital Brasileira de Teses e Dissertações), considerando todos os trabalhos acadêmicos disponíveis nessas bases até 2019 . $\mathrm{Na}$ Scielo, utilizou-se os termos chave: EJA e Física, resultando em quatro artigos, sendo que um deles não estava relacionado ao tema. Na BDTD, utilizou-se o termo Ensino de Física na EJA, o qual retornou 75 resultados, dos quais, apenas 25 continham Física e Educação de Jovens e Adultos (EJA) no título ou nas palavras-chave. $\mathrm{Na}$ presente seção, comentaram-se alguns dos trabalhos encontrados, considerados mais relevantes para a discussão do presente artigo.

Silva (2017), em sua dissertação intitulada Análise de Material Didático de Física para EJA: do TELECURSO ao PNLD ${ }^{8}$-EJA, destaca alguns dos problemas encontrados no Ensino de Física na EJA no Brasil. Para o autor, a formação inadequada dos professores e a limitação de materiais didáticos específicos disponíveis têm contribuído para a execução de um currículo precário. Silva ainda relata que, durante a sua trajetória docente em uma escola pública, observou a falta de livros didáticos e também a falta de livros voltados para a EJA, o que o levava a realizar uma adaptação dos poucos livros que haviam voltados ao ensino regular. Por isso, a dissertação de Silva (2017) teve como objetivo analisar três materiais didáticos (TELECURSO, Acervo-EJA e PNLD-EJA) voltados para jovens e adultos. Ele buscou compreender sua organização, de que maneira o material pretendia auxiliar os alunos e os docentes e, ainda, se o material didático apresentava indícios 
de compatibilidade com o Encceja. Após a análise dos materiais, o autor observou que esses apresentavam uma abordagem da Física a partir do cotidiano do aluno, valorizando também o conhecimento adquirido ao longo da vida dos alunos da EJA.

Estudos como os de Barbosa (2018) e Gama (2015) mostram caminhos alternativos na elaboração de produtos educacionais na área de Ensino de Física para a EJA. Em sua dissertação, Barbosa (2018) buscou compreender as possíveis contribuições de atividades lúdicas de Física no contexto da EJA, propondo seis alternativas lúdicas, cujos temas abordados são do campo da Mecânica, Termologia e Física Elétrica referentes ao $3^{\circ}$ segmento da EJA, séries correspondentes ao Ensino Médio regular. Os resultados apontam que cinco das seis atividades propostas cumpriram tanto com a função lúdica quanto à educativa, transformando, segundo o autor, o ensino e a aprendizagem dos conceitos de Física divertido e estimulante.

Já Gama (2015), investigou as contribuições de uma proposta de Ensino de Física para a EJA apoiada no conceito de aprendizagem significativa de Ausubel ${ }^{9}$, utilizando atividades experimentais demonstrativas como principal estratégia de ensino. Com a aplicação de algumas atividades experimentais demonstrativas sobre Hidrostática, oito questionários, dois mapas conceituais, uma avaliação tradicional ${ }^{10}$, dados provenientes das atividades experimentais demonstrativas e de uma prática investigativa (gravações em áudio e anotações no diário de campo da professora-pesquisadora), Gama concluiu que as atividades experimentais demonstrativas se revelaram eficientes como uma proposta de avaliação processual e que também levaram o Ensino de Física para além da sala de aula.

Krummenauer e Wannmacher (2016) realizaram uma pesquisa, com o auxílio de questionários estruturados, com o objetivo de identificar a percepção de 16 professores de Física, que atuavam na EJA, em duas cidades da região do Vale do Rio dos Sinos - RS, acerca do interesse dos alunos da EJA nas aulas de Física. Os resultados apontaram que 11 desses professores percebiam a desmotivação dos alunos nas aulas e todos os 16 professores entrevistados afirmaram implementar as mesmas metodologias de ensino usadas no ensino regular. O que indica a falta de mudança de metodologia de ensino para a EJA e, consequentemente, a não observância das especificidades desta modalidade

Buscando dados sobre os imaginários de licenciandos em Física quanto à EJA e ao Ensino de Física nessa modalidade, perspectiva semelhante ao que se propôs no presente estudo, Jesus e Nardi (2016) realizaram uma pesquisa com 17 licen- 
ciandos em Física de uma universidade pública do interior do estado de São Paulo, utilizando questionários, e sistematizaram seus resultados no Quadro 1.

Quadro 1: Aspectos dos imaginários dos licenciandos (JESUS; NARDI, 2016, p. 67).

Aspectos dos imaginários de licenciandos em física quanto à EJA e ao ensino de física nessa modalidade

a. Conhecem a expressão "EJA", mas não sabem como essa modalidade se organiza;

b. Relacionam a educação de adultos apenas à alfabetização;

c. Caracterizam a EJA pela sua carga horária reduzida - se comparada ao ensino regular - sendo este um fator preocupante;

d. Sugerem a simplificação dos conteúdos;

e. Preocupam-se em relacionar os conceitos científicos com o cotidiano dos alunos;

f. Vinculam a EJA à uma imagem negativa;

g. Reconhecem especificidade da modalidade;

h. Estabelecem interdiscursos com a legislação, para justificar a necessidade dos cursos de EJA;

i. Destacam interesses políticos e econômicos que possam estar envolvidos na modalidade.

Na mesma perspectiva investigativa, Montenegro (2016) realizou uma pesquisa com o principal objetivo de verificar como as discussões da realidade da EJA se expressam dentro dos cursos de formação inicial de licenciatura em Química e licenciatura em Física da Universidade Estadual da Paraíba. Para isso, primeiro foram observados os documentos oficiais (Pareceres e Diretrizes) e técnicos (Projeto Político Pedagógico) que regem os cursos de licenciatura mencionados, a fim de tentar observar qual o perfil do educador que se espera formar. Em um segundo momento, utilizou-se de entrevista semiestruturada a fim de verificar o que os 7 professores formadores tinham a dizer sobre a formação voltada para a EJA. Em seus resultados, o autor percebeu que há falta de orientação voltada para a EJA nos documentos oficiais que orientam os documentos técnicos, tornando esse diálogo ainda distante. $\mathrm{O}$ autor ainda afirma que diante das falas dos professores formadores, ficou perceptível que, para os entrevistados, não há discussão que seja voltada para uma formação inicial específica para a modalidade EJA nos referidos cursos e tal fato tem sido um obstáculo ao professor formador e aos professores em formação.

A partir desse panorama, é possível perceber o quanto se faz necessária a ampliação da discussão sobre como tem se dado a formação de professores para o Ensino de Física na EJA, tendo em vista suas implicações nos processos de ensino e aprendizagem e, consequentemente, no sucesso escolar dos alunos. 


\section{Caminhos metodológicos}

A presente pesquisa foi de caráter qualitativo, na qual pretendeu-se verificar quais os entendimentos de licenciandos em Física sobre o conceito, os sujeitos, o ensino e a aprendizagem na EJA. Para isso, criou-se um roteiro de entrevista semiestruturada (Quadro 2), realizada individualmente e gravada em áudio. A escolha por gravação de áudio se deu para que a conversa ocorresse mais livremente, sem a necessidade de realizar muitas anotações durante a entrevista.

Quadro 2: Roteiro de entrevista semiestruturada.

1. O que você sabe sobre a Educação de Jovens e Adultos (EJA)?

2. O que é a EJA?

3. Você já teve algum contato com essa modalidade de ensino? Qual?

4. Quem são os alunos que podem cursar a EJA?

5. Por que você acredita que existem cursos de EJA?

6. Como você pensa num planejamento de aula para os alunos da EJA?

7. Cite exemplos de atividades que podem ser desenvolvidas na EJA.

8. Quais metodologias você acredita serem adequadas para serem desenvolvidas em turmas de EJA?

9. Você gostaria de lecionar na EJA?

10. Existem diferenças entre esses alunos e os do ensino regular? Quais?

11. Caracterize o sujeito da EJA.

12. Como você acredita que ocorre a aprendizagem dos alunos da EJA?

13. Em quais disciplinas do curso de Licenciatura você lembra ter estudado ou discutido sobre a EJA?

14. Quais comentários você gostaria de adicionar?

$\mathrm{Na}$ entrevista semiestruturada, o pesquisador formula um roteiro com questões principais e complementa-o com outras questões, à medida que surjam durante o desenvolvimento da entrevista (MANZINI, 1991). Gaskell (2011) afirma que a entrevista qualitativa fornece uma descrição detalhada de um meio social específico. Além disso, com entrevistas individuais, é possível conseguir detalhes mais ricos a respeito de experiências pessoais, decisões e sequências das ações. Nesse sentido, as entrevistas proporcionaram: uma maior flexibilidade, favorecendo a adaptação às características das pessoas e às circunstâncias em que se desenvolveram as entrevistas; captar a expressão corporal dos entrevistados, bem como a tonalidade da voz e a ênfase nas respostas; dar visibilidade aos entendimentos e opiniões de 
sujeitos que são licenciandos em Física; e, ainda, garantir maior sinceridade nas respostas que foram dadas.

A pesquisa teve como campo de estudo uma universidade pública federal, localizada em uma cidade da Região Metropolitana de Porto Alegre. A cidade é considerada de zona rural e possui uma população de mais de 40 mil habitantes.

Os sujeitos da pesquisa foram todos os 12 alunos de um curso de licenciatura com habilitação em Física, a partir do terceiro semestre. As 12 entrevistas tiveram duração média de 10 minutos cada e todos os participantes assinaram um termo de consentimento livre e esclarecido ${ }^{11}$.

A análise das entrevistas deu-se através da Análise Temática. Segundo Braun e Clarke (2006, p. 79, tradução nossa), a análise temática é um método qualitativo de análise de dados que busca "identificar, analisar e relatar padrões (temas) dentro dos dados. Ela minimamente organiza e descreve o conjunto de dados em (ricos) detalhes". Conforme explicado por Braun e Clarke (2006), os temas emergentes da análise temática podem variar de acordo com questões delineadas e devem ser considerados antes e durante as análises. Levou-se em conta, neste estudo, que as questões delineadas seriam categorias pré-definidas de análise, buscando responder o objetivo geral deste trabalho. As categorias definidas foram: a) o conceito; b) os sujeitos; c) o ensino; e d) a aprendizagem na EJA.

No quadro 3, Braun e Clarke (2006) apresentam os estágios da Análise Temática, mas ressaltam não haver uma ordem fixa.

Quadro 3: Estágios da análise temática (BRAUN; CLARKE, 2006, p. 87, tradução nossa).

\begin{tabular}{|l|l|}
\hline \multicolumn{1}{|c|}{ Estágio } & \multicolumn{1}{c|}{ Descrição do processo } \\
\hline $\begin{array}{l}\text { 1. Familiarizando-se com } \\
\text { seus dados }\end{array}$ & Transcrição dos dados, leitura e releitura dos dados, apontamento de ideias iniciais. \\
\hline $\begin{array}{l}\text { 2. Gerando códigos } \\
\text { iniciais }\end{array}$ & $\begin{array}{l}\text { Codificação das características interessantes dos dados de forma sistemática em } \\
\text { todo o conjunto de dados, e coleta de dados relevantes para cada código. }\end{array}$ \\
\hline $\begin{array}{l}\text { 3. Buscando por temas } \\
\text { 4. Revisando temas }\end{array}$ & $\begin{array}{l}\text { Agrupamento de códigos em temas potenciais, reunindo todos os dados relevantes } \\
\text { para cada tema potencial. }\end{array}$ \\
\hline temas & $\begin{array}{l}\text { Verificação se os temas funcionam em relação aos extratos codificados (nível 1) } \\
\text { e ao conjunto de dados inteiro (nível 2), gerando um "mapa" temático da análise. }\end{array}$ \\
\hline $\begin{array}{l}\text { 5. Definindo e nomeando } \\
\text { 6roduzindo o relatório }\end{array}$ & $\begin{array}{l}\text { Nova análise para refinar as especificidades de cada tema, e a história geral conta- } \\
\text { da pela análise; geração de definições e nomes claros para cada tema. }\end{array}$ \\
\hline $\begin{array}{l}\text { A última oportunidade para a análise. Seleção de exemplos vívidos e convincentes } \\
\text { do extrato, análise final dos extratos selecionados, relação entre análise, questão } \\
\text { da pesquisa e literatura, produzindo um relatório acadêmico da análise. }\end{array}$ \\
\hline
\end{tabular}


Em um primeiro momento, após a realização das entrevistas, fez-se as transcrições das mesmas. De acordo com o andamento das transcrições, realizou-se a leitura flutuante das transcrições (Estágio 1). A transcrição se deu de forma manual e foi importante para uma primeira reflexão.

Durante a leitura atenta dos dados, considerando as categorias supracitadas: a) o conceito; b) os sujeitos; c) o ensino; e d) a aprendizagem na EJA, destacaram-se as primeiras temáticas relevantes, por serem reincidentes (Estágio 2 e 3). No Quadro 4, apresenta-se o esquema de análise utilizado nos processos de e, em seguida, a sinterização em temáticas dentro das categorias encontradas no excerto.

Quadro 4: Exemplo dos Estágios da Análise Temática realizada.

\begin{tabular}{|c|c|c|}
\hline Transcrição & Códigos iniciais & $\begin{array}{l}\text { Categorias e seus } \\
\text { respectivos temas }\end{array}$ \\
\hline $\begin{array}{l}\text { Entrevistador: Como você pensa num planejamento de aula } \\
\text { para os alunos da EJA? } \\
\text { Licenciando I: Eu acho que primeiramente, assim, se eu fosse } \\
\text { a docente eu analisaria a faixa etária que eu tenho dentro da } \\
\text { sala de aula para mesclar, porque às vezes tu pode ter mais } \\
\text { jovens do que adultos né. } \\
\text { Entrevistador: [expressão de concordância]. } \\
\text { Licenciando I: Mas tem uma pessoa que já tem mais de } 50 \\
\text { anos tem que ter um tipo de abordagem diferente, então ini- } \\
\text { cialmente, provavelmente eu adotaria uma postura, assim, } \\
\text { mais de conhecer quem é a minha turma para a partir de uns } \\
\text { dois, três encontros montar um currículo através disso. }\end{array}$ & $\begin{array}{l}\text { Verificar a faixa etária } \\
\text { dos alunos antes de } \\
\text { planejar aulas. } \\
\text { Ensino diferente para } \\
\text { a EJA. } \\
\text { Conhecer os alunos } \\
\text { para planejar aulas. }\end{array}$ & $\begin{array}{l}\text { ENSINO } \\
\text { - Sondagem da turma } \\
\text { - Diferente do ensino } \\
\text { regular } \\
\text { SUJEITOS } \\
\text { - Jovens } \\
\text { - Adultos } \\
\text { - Idosos }\end{array}$ \\
\hline
\end{tabular}

Por fim, iniciou-se o processo de escrita dos resultados encontrados (Estágio 6), no qual realizou-se também uma revisão dos temas encontrados e uma melhor definição dos mesmos (Estágio 4 e 5).

\section{Resultados e discussões}

A partir das doze entrevistas realizadas com os licenciandos de Física de um curso de licenciatura com habilitação em Física de uma universidade pública federal na Região Metropolitana de Porto Alegre, foi possível realizar uma leitura flutuante das transcrições e identificar quais perspectivas os licenciandos em Física possuem sobre o que é, sobre os sujeitos, sobre o ensino e a aprendizagem na Educação de Jovens e Adultos. 
A partir das temáticas encontradas para o conceito de EJA, observou-se que os licenciandos entendem, em geral, que a EJA se trata da possibilidade de conclusão dos ensinos fundamental e médio (licenciandos $\mathrm{A}^{12}, \mathrm{~B}, \mathrm{E}, \mathrm{F}, \mathrm{I}, \mathrm{J}, \mathrm{K}$ e L). Para o licenciando A, a EJA “é uma opção, que é fazer o ensino fundamental e ensino médio, já para o licenciando B, a EJA é para o pessoal conseguir tirar ${ }^{13}$, ter o diploma de ensino médio" e, por fim, para o licenciando I, a EJA "é um mecanismo, assim, que boa parte da sociedade usa para conseguir a formação do ensino médio".

Chama a atenção, nas narrativas, que quase metade dos licenciandos admitem não saber como a EJA funciona (B, F, H, I e L). Em falas como: "olha, basicamente, é que o pessoal que não tem interesse ou que não conseguiu terminar no tempo adequado vai e faz, mas eu não sei como realmente funciona se é só ir assistir à aula e fazer a prova ou só fazer a prova, não sei, basicamente, é isso que eu sei (licenciando F); eu não sei o que é Educação de Jovens e Adultos" (licenciando B); "sobre a Educação de Jovens e Adultos eu sei pouco, na verdade" (licenciando L); é possível observar o fato descrito acima. Esse resultado está de acordo com o encontrado por Jesus e Nardi (2016) em seu artigo - que teve como objetivo investigar imaginários de um grupo de licenciandos em Física sobre a EJA e o ensino nessa modalidade. Segundo os pesquisadores, a "ideia de como a modalidade se organiza parece não estar clara para os futuros docentes" (JESUS; NARDI, 2016, p. 57).

Ao contrário dos achados de Jesus e Nardi (2016); os quais mostram que os licenciandos, ao serem questionados sobre a EJA, referem-se somente ao processo de alfabetização, esquecendo que essa modalidade também oferece continuidade dos estudos para pessoas que já são alfabetizadas; os licenciandos E e J assinalaram que a EJA não se refere somente à alfabetização. Falas como as descritas a seguir demonstram que esses licenciandos entendem a EJA para além da alfabetização.

"eu acho que vai muito além do da daquela parte de alfabetização né" (licenciando E);

"eu achava que era pra alfabetizar, eu acredito que é pra alfabetizar jovens e adultos, no caso, pessoas que não têm esse conhecimento, até porque se for só pra se formar tem esses outros que são o NEJA ${ }^{14}$, isso, aquilo eu não sei se EJA, NEJA, e todas as coisas são educação para jovens e adultos, a mesma coisa, mas, acredito que é voltado, principalmente, para ensino de alfabetização, de aprender o básico, de conta" (licenciando J).

Já o licenciando G, apenas mencionou que também é objetivo da EJA aumentar os índices de alfabetização no país, enquanto os demais não fizeram referência à alfabetização em suas respostas. 
Para os licenciandos B, C e E, a EJA se constitui em uma modalidade de ensino para pessoas que já passaram da idade regular para estudar. Isso porque, entendem a EJA como um espaço onde: "eles dão aula pro pessoal que é mais velho, à noite, que tem mais de 18 anos" (licenciando B); “o que eu sei é pra quem o EJA é, pra quem já passou da idade que seria pra estar no ensino normal" (licenciando $\mathrm{C}$ ).

O licenciando G mostrou conhecer o termo Encceja, porém, confundiu-se com o de EJA, no seguinte trecho: "as pessoas que a, a, digamos, abandonaram, deixaram pra se formar depois e que tem uma idade mais avançada, elas entram no EJA pra, pra conseguir o diploma de ensino médio [...] Acredito que, eu acho que o fundamental é o Encceja, né, algo do gênero".

Oportuno dizer que, chamou a atenção os licenciandos não comentarem sobre a modalidade EJA a distância, comumente oferecida em redes particulares de ensino. Vale lembrar que a partir de 2018 as novas diretrizes curriculares para o ensino médio limitaram o uso do EaD em até 80\% para a EJA (FAJARDO, 2018).

A partir disso, é possível observar que os estudantes de licenciatura com habilitação em Física, em sua maioria, têm um conhecimento diversificado e, em alguns momentos, superficial do que venha a ser EJA. Contudo, os que já tiveram algum contato com a modalidade, seja por meio de algum familiar ou por meio de situações produzidas no curso de licenciatura, trazem em suas narrativas mais elementos sobre o conceito da Educação de Jovens e Adultos.

Pensando nos sujeitos frequentadores da EJA, identificou-se um conjunto amplo de características utilizadas para definir os alunos da Educação de Jovens e Adultos. Tal achado, possivelmente, reflete o diversificado público que a EJA atende (LOCH, 2009).

Os resultados com mais incidência estão apresentados no Quadro 5.

Quadro 5: Temáticas mais frequentes para definir os sujeitos da EJA.

\begin{tabular}{|l|c|c|}
\hline \multicolumn{1}{|c|}{ Temáticas } & Licenciandos & Frequência \\
\hline Pessoas que trabalham & A, B, D, E, F, G, I e J & 8 \\
\hline São maiores de 18 anos & A, B, D, H, I, J, K e L & 8 \\
\hline Pessoas mais velhas & A, B, D, F, G e J & 6 \\
\hline Alunos que não conseguiram se formar na idade certa & B, F, H, I e J & 5 \\
\hline Não concluíram o ensino fundamental e o médio no ensino regular & A, G L e K & 4 \\
\hline Jovens & H, I, J e L & 4 \\
\hline
\end{tabular}


Oito dos doze licenciandos sinalizaram que os sujeitos da EJA são maiores de 18 anos. Essa compreensão, porém, mostra certo desconhecimento da idade mínima de ingresso de alunos na EJA, pois para o ensino fundamental é de 15 anos e para o ensino médio é de 18 anos (BRASIL, 2000). Apenas o licenciando F mencionou a idade inicial de 16 anos.

Apenas quatro, dos doze licenciandos, mencionaram “jovens”, em suas respostas. Este dado chama a atenção, pois segue na contramão do que é apresentado no Censo Escolar de 2018 (INEP, 2019), no qual cerca de 52\% dos alunos matriculados na EJA possuem idades entre 14 e 24 anos. Isso revela que, boa parte dos licenciandos em Física acreditam que os alunos da EJA são, em sua maioria, adultos e/ou idosos.

A análise das entrevistas, também aponta que algumas das características descritas pelos licenciandos expressam um certo preconceito relacionado ao interesse dos sujeitos frequentadores da EJA com os estudos, os quais remetem a entendimentos de que estes alunos: não se interessaram em estudar antes (licenciando F), não gostavam de estudar (licenciando $\mathrm{A}$ ), não querem estudar e dormem nas aulas (licenciando B), não fazem as atividades em casa (licenciando J), geralmente, não estão interessados em aprender (licenciando $\mathrm{H}$ ), possuem deficiência (licenciando D) e só querem se formar (licenciando E). Oportuno destacar que esses olhares negativos sobre os alunos da EJA - sete dos doze licenciandos - implicará na forma como estes licenciandos irão elaborar, ministrar suas aulas e contribuir na formação de seus alunos.

Segundo Pinto (2010, p. 91), ao subestimar a educação de um adulto, o professor "supõe que a educação (alfabetização de adultos) consiste na 'retomada do crescimento' mental de um ser humano que, culturalmente, estacionou na fase infantil. O adulto é considerado, assim, um 'atrasado"'. Em relação a isso, Giovanetti (2007) diz que os educadores devem superar essa negatividade relacionada à EJA, para que não se assuma uma postura preconceituosa e estigmatizada. Além disso, Arroyo (2007, p. 7) destaca que

Quem convive com esses jovens e adultos deve se fazer essa pergunta: de onde esses jovens e adultos que freqüentam a EJA estão mais próximos? Seria dos jovens e adultos das camadas médias? Ao contrário, estão cada vez mais distantes. Na pobreza, miséria, sub-emprego, vulnerabilidade.

Em relação às condições de vida dos alunos da EJA, o licenciando I menciona que "tem uma grande parcela da sociedade que opta por desistir da formação, por- 
que às vezes é difícil se deslocar, às vezes não tem motivação pra continuar, falta recurso... financeiros e que geralmente, os alunos da EJA vêm de comunidades mais pobres, sem incentivo. Onde, na grande maioria dos casos, o aluno não, não decide continuar estudando, porque ele precisa trabalhar pra ajudar a família a se manter". Esse entendimento está de acordo com Souza (2012), quando afirma que esses alunos têm trajetórias de vida marcadas por exclusão, perdas e esperanças.

Observou-se nos resultados certa relação entre as falas de ensino e aprendizagem, pois entende-se que o modo como os licenciandos pensam que o aluno da EJA aprende, implicará nas formas como planejarão e desenvolverão suas aulas. Oportuno dizer que três, dos doze, licenciandos não falaram sobre a aprendizagem, mesmo que uma das questões fizesse referência ao tema.

No que se refere à aprendizagem dos alunos da EJA, um terço dos licenciandos entendem que essa aprendizagem ocorre de forma lenta (C, E, F e J). Já os licenciandos $\mathrm{A}$ e $\mathrm{H}$ compreendem que a aprendizagem nessa modalidade se baseia em memorização e, os licenciandos A e C, que esses alunos possuem mais dificuldades.

Segundo o licenciando F, os alunos da EJA aprendem mais lentamente "pelo fato de que eles não estão mais tão acostumados com a sala de aula, eles têm outras preocupações [...] então, eles têm trabalho, tem muitas outras coisas, então isso eu acho que prejudica um pouco mais". Já para o licenciando J, "é muito mais difícil tu trabalhar a aprendizagem de um adulto e de um jovem, porque a cabeça dele vai tá voltada para outras quinhentas coisas e não somente para aquilo que está acontecendo em sala de aula [...], diferente da criança que ela consegue ocupar a mente dela só com aquele conteúdo [...], então, a aprendizagem mais é demorada por esse lado".

Sobre a aprendizagem se dar através da memorização, o licenciando A fala que "eu acho que é memorização, [...] talvez, aprender alguma coisa seja mais difícil, então, talvez seja na base da memorização, da formulinha lá, tentar decorar formulinha".

Nota-se de forma reincidente a descrição de processos de ensino simplificados, descrito por meio de ideias como, repetitiva (licenciando L), resumida (licenciando D) e técnica (licenciando L), também são mencionadas como características da aprendizagem de jovens e adultos.

Em relação ao ensino para a Educação de Jovens e Adultos, há certa concordância de que ele deve ser diferente do que é desenvolvido no ensino regular (licenciandos 
B, C, D, E, F e G), em especial por considerarem se tratar de um ensino que deve ser ministrado de forma resumida (licenciandos A, B, C, F, H, L e K) e facilitada (licenciandos $\mathrm{H}$ e L). Esse entendimento de que o ensino na EJA é ministrado de forma resumida está de acordo com os achados de Jesus e Nardi (2016) e Lambach e Marques (2009), nos quais os entrevistados também caracterizaram a EJA como um ensino resumido. As seguintes falas, evidenciam o caráter resumido, popularmente atribuído à Educação de Jovens e Adultos: "teria que ser bem resumido na verdade, que tudo que teria que se ver em um ano, eles teriam que ver em 6 meses" (licenciando A); "eu acho que pode ser qualquer uma atividade que tu fosse no, no ensino normal, só que tu teria que adequar, adaptar em menos tempo, né, e não cobrar tanto" (licenciando C); "o EJA perde um pouco da, do conteúdo escolar em si. Já na escola a gente já perde e no EJA, como ele é um tempo mais diminuído, tem menos carga horária, o pessoal perde também bastante conteúdo" (licenciando F).

$\mathrm{Na}$ contramão desse entendimento, os licenciandos $\mathrm{C}$ e $\mathrm{K}$ falam em um ensino igual ao do ensino regular, envolvendo atividades para fazer em casa, experiências rápidas, como por exemplo, a montagem de circuitos elétricos.

A experimentação física emergiu como uma prática pedagógica a ser desenvolvida em salas de aula da EJA (licenciandos A, F, K, J e L). Segundo o licenciando J, é interessante realizar em uma sala de aula da EJA "algum tipo de experimento, assim, mais dinâmico, porque é uma coisa que vai ter a atenção deles e que pode instigar uma discussão". Segundo Laburú, Mamprin e Salvadego (2011, p. 20) é por meio das atividades experimentais, que "o estudante pode ser estimulado a não permanecer no mundo dos conceitos e das linguagens, desencadeando a oportunidade de relacioná-las ao mundo empírico".

De acordo com a pesquisa de Lambach e Marques (2009), os professores de Química na EJA valorizam muito as atividades empíricas por meio de práticas de laboratório, com o objetivo de ilustrar e reforçar o conteúdo teórico. Além disso, a dissertação de Gama (2015), já mencionada na seção sobre o Ensino de Física na EJA, apostou em aplicações de atividades experimentais demonstrativas para estudar Hidrostática com alunos da EJA, obtendo bons resultados. Isso mostra que atividades experimentais podem contribuir para o ensino de jovens e adultos.

Para os licenciandos E, L e F, o ensino na EJA deve estar relacionado às vivências e o cotidiano dos alunos, o que está de acordo com os resultados também encontrados por Lambach e Marques (2009, p. 226), em seu artigo "Ensino de Química 
na Educação de Jovens e Adultos: relação entre estilos de pensamento e formação docente". No estudo, os autores constataram o interesse de professores de Química em "participar de cursos que considerem a experiência extra-escolar dos educandos, levando em conta o seu perfil e a sua realidade".

Em relação ao ensino utilizando as vivências dos alunos, autores como Pinto (2010) alertam que se deve considerar esse sujeito como um participante ativo de uma comunidade e, também, as suas experiências de vida. Sobre aproveitar a experiência de vida dos alunos, Paulo Freire (2020, p. 31-32) questiona

\begin{abstract}
por que não aproveitar a experiência que têm os alunos de viver em áreas da cidade descuidadas pelo poder público para discutir, por exemplo, a poluição dos riachos e dos córregos e os baixos níveis de bem-estar das populações, os lixões e os riscos que oferecem à saúde das gentes.
\end{abstract}

Ainda sobre isso, Loch (2009) lembra que os educadores da EJA devem considerar os saberes e experiências do educando como parte fundamental no processo de ensino e aprendizagem.

Como reflexo do entendimento de que a aprendizagem dos alunos da EJA ocorre de forma lenta (licenciandos C, E, F e J), o Ensino de Física é pensado como "matematicamente mais leve" (licenciando A), facilitado (licenciandos $\mathrm{H}$ e L) e, ainda, exigindo uma maior paciência aos professores (licenciando E).

Chama a atenção que a ideia de um ensino "matematicamente mais leve" (licenciando A), também aparece nos resultados de Jesus (2012, p. 119) quando, na fala de um entrevistado, é dito: "imagino que as aulas terem mais conceitos do que contas e quando elas aparecem devem ser as mais simples". A autora comenta que há um equívoco nessas ideias, pois, os licenciandos "parecem relacionar esta abordagem com a ausência da ferramenta matemática vista como um empecilho para o ensino e que a exclusão desse instrumento irá facilitar a assimilação dos conceitos para os estudantes" (JESUS, 2012, p. 139). Entretanto, diversos autores recomendam que o Ensino de Física seja mais conceitual, por acreditarem que a aprendizagem conceitual é imprescindível para um bom entendimento da Física e, inclusive, é condição necessária para a resolução de problemas (SILVEIRA; MOREIRA; AXT, 1996; LASRY; MAZUR; WATKINS, 2008).

Falas como "depende muito de como é a turma pra mim planejar a aula" (licenciando D) e "então, inicialmente, provavelmente, eu adotaria uma postura, assim, mais de conhecer quem é a minha turma pra a partir de uns dois, três encontros, 
montar um currículo através disso" (licenciando I), asseveram a preocupação dos alunos em relação à sondagem dos conhecimentos dos alunos para a elaboração do planejamento de aula (licenciandos D, E, I e J). Esse movimento de realizar uma sondagem inicial numa turma da EJA também é comentada por Loch (2009).

Percebeu-se a opção pelo ensino tradicional como metodologia a ser empregada na EJA pelos licenciandos C, D, H, I e K. Entretanto, os licenciandos D e K falaram que primeiro utilizariam o ensino tradicional ${ }^{15}$ e depois readaptariam, caso não funcionasse. Já o licenciando $\mathrm{H}$ citou a pedagogia diretiva, enquanto o licenciando C mencionou uma aula direta, sem enrolação e o licenciando I afirmou não saber se conseguiria escapar do ensino tradicional. Houve ainda, a ideia de mesclar metodologias ativas com tradicionais (licenciandos $\mathrm{J}$ e L). Isso mostra que apesar da presença significativa do ensino tradicional como perspectiva de trabalho a ser desenvolvida pelos futuros professores, é possível constatar uma abertura para metodologias ativas de ensino, o uso da experimentação física, a preocupação com a experiência de vida e o cotidiano dos alunos.

Destacam-se as respostas à questão 9, onde os licenciandos deveriam responder se gostariam de lecionar na EJA. Dos doze entrevistados, sete responderam que sim (licenciandos D, E, F, G, I, J e K), três que apenas por necessidade (licenciandos A, B e H), um que não (licenciando B) e outro que não sabe (licenciando K). O que se observa, é que há interesse do grupo entrevistado, em sua maioria, em ministrar aulas na Educação de Jovens e Adultos, apesar de acusarem fragilidades em sua formação inicial.

Ao perguntar aos licenciandos em quais disciplinas do curso de licenciatura lembravam ter estudado ou discutido sobre a EJA, as disciplinas citadas foram Didática (licenciandos A, B, C, J e L), Organização Escolar e Trabalho Docente (licenciandos A, G, K e L), Ciências e Sociedade (licenciando J) e Oficinas ${ }^{16}$ (licenciando J). Os demais licenciandos (D, E, F, H e I) alegaram nunca terem estudado ou discutido sobre a EJA em sala de aula. Conforme as falas dos licenciandos, entende-se que houve pouca discussão sobre a EJA durante a sua formação inicial. A exemplo, citam-se: "acredito que uma foi Organização Escolar, quando a gente estudou a questão das bases e estava ali inserido o, o nome EJA né, ah, mas não, não tem um aprofundamento (licenciando G); na faculdade a gente não tem isso, [...], eu já estou aqui há quase dois anos e, nesse tempo todo, nunca, nunca vieram falar assim beleza agora vocês vão lá a noite dar uma aula no EJA (licenciando E); 
então, assim, a gente falou sobre. Mas entrar a fundo mesmo, eu ainda não entrei em nenhuma cadeira. Didática que a gente debateu mais mesmo" (licenciando J).

\section{Considerações finais}

O presente estudo permitiu observar quais as perspectivas de licenciandos em Física, acerca do conceito, dos sujeitos, do ensino e da aprendizagem na Educação de Jovens e Adultos. Para compreender tais perspectivas optou-se por entrevistar doze licenciandos de um curso de licenciatura com habilitação em Física. Através das entrevistas, percebeu-se que os futuros professores sabem pouco sobre as informações necessárias para atuar na modalidade de Educação de Jovens e Adultos, resultado semelhante aos encontrados na literatura.

De acordo com as análises realizadas, os achados da pesquisa indicam que os licenciandos: a) pouco sabem sobre o que é a EJA, ressalvados aqueles que já possuíram algum contato familiar; b) entendem os alunos da EJA como um público diversificado; c) entendem que os alunos da EJA vêm de uma trajetória de desinteresse pelos estudos do ensino regular; d) apostam, preferencialmente, em metodologias tradicionais, sugerindo, também, metodologias ativas e a mescla dessas; e) mencionam a importância da realização de sondagem junto aos alunos, para o planejamento da aula; f) e acreditam que os alunos da EJA aprendem de forma lenta e dificultosa.

Com os poucos entendimentos dos licenciandos em Física para a docência na EJA, é possível inferir que a EJA ainda ocupa lugar de pouco destaque na proposta curricular do curso em questão. Para uma formação adequada para a docência na EJA, é preciso que o futuro professor tenha acesso a um conjunto de saberes e práticas, por meio dos quais veja seu aluno como um universo de possibilidades e tenha condições de desenvolver um ensino capaz de promover a construção do conhecimento de seus alunos. Por fim, conclui-se que os resultados encontrados mostram a necessidade de maior investimento nos estudos sobre o Ensino de Física na EJA, bem como, do repensar das diretrizes curriculares e dos currículos dos cursos de licenciatura.

Para além, entende-se que esse assunto deva ser ainda mais abordado. Isso porque, a presente pesquisa sobre o entendimento de licenciandos acerca da EJA sinaliza a necessidade do debate sobre possíveis ações envolvendo: a inclusão de 
uma disciplina específica na grade curricular dos cursos de licenciatura; a inserção dos estudos sobre a modalidade EJA em ementas de disciplinas pedagógicas e, também, da promoção de palestras, seminários, ciclos de debates e rodas de conversas sobre o tema.

\section{Physics student's perspective about youth and adult education}

\section{Abstract}

This study sought to understand what are the understandings of the undergraduate physics students, from the Physics Undergraduate of the Metropolitan Region of Porto Alegre, about the concept, the students, the teaching and learning in Youth and Adult Education (EJA, in Portuguese). For this purpose, we carried out interviews recorded in audio and subsequently analyzed from the point of view of Braun and Clarke's thematic analysis. According to the analyses performed, the findings pointed out that undergraduates: know little about EJA, except for those who have had some family contact; perceive EJA students as a diverse group; presents a biased discourse disqualifying EJA students; tends to prefer traditional teaching strategies, also suggesting active methods and a mixed approach; mention the importance of conducting an investigation with students in order to plan the classes; believe that EJA students learn slowly and with difficulty. Finally, the results point to the need to rethink the undergraduate physics curriculum and to invest more in research on Physics Teaching in EJA.

Keywords: Youth and Adult Education, Physics Teaching, Physics Teacher Training, Teaching and Learning in EJA, Thematic Analysis.

\section{Notas}

1 Segundo o documento de Diretrizes Curriculares Nacionais para a Formação de Professores em Nível Superior (BRASIL, 2015), os cursos de licenciatura habilitam para o exercício da docência na Educação Básica, incluindo a EJA, uma das modalidades da Educação Básica.

2 O Parecer 1304/2001 define as Diretrizes Nacionais Curriculares para os Cursos Superiores de Física.

3 Permite ao pesquisador realizar outras perguntas, para além das que compõem o roteiro, conforme os desdobramentos da entrevista. É também conhecida como semidiretiva ou semi-aberta (MANZINI, 1991).

5 O Decreto n⿳ 5.840, de 13 de julho de 2006, institui, no âmbito federal, o Programa Nacional de Integração da Educação Profissional com a Educação Básica na Modalidade Proeja.

6 O Parecer 6/2010 tem como assunto: Reexame do Parecer CNE/CEB nº 23/2008, que institui Diretrizes Operacionais para a Educação de Jovens e Adultos - EJA, nos aspectos relativos à duração dos cursos e idade mínima para ingresso nos cursos de EJA; idade mínima e certificação nos exames de EJA; e Educação de Jovens e Adultos desenvolvida por meio da Educação a Distância.

7 Os autores utilizam o termo novo, pois esse seria o primeiro ano que a escola ofereceria a EJA.

8 Plano Nacional do Livro Didático. 
9 Segundo Moreira (2011), a aprendizagem significativa de Ausubel diz que o conhecimento novo deve sempre estar relacionado com algum conhecimento prévio do aluno e que esse sujeito precisa apresentar uma predisposição e intencionalidade em aprender.

10 A avaliação tradicional, a qual a autora se refere, contou com 16 questões abordando os conceitos estudados durante a intervenção, com o objetivo de investigar a compreensão dos alunos acerca da temática Hidrostática.

11 Os termos de consentimento livre e esclarecido estão mantidos em arquivo físico, e, os outros dados da pesquisa estão em arquivo digital, sob guarda e responsabilidade, por um período mínimo de cinco anos após o término desta pesquisa.

12 Letra indicada para cada licenciando conforme a ordem de realização das entrevistas.

13 A expressão tirar aqui significa obter.

14 Núcleo de Educação de Jovens e Adultos.

15 De acordo com Silva (2005), o ensino tradicional está pautado na técnica, voltada para as ocupações profissionais, no qual o papel do professor é o de detentor e transmissor do conhecimento aos alunos. Segundo Becker (1994), na pedagogia diretiva, o professor entende que o aluno apenas aprenderá quando ele transmite o conhecimento, sendo este o mito da transferência do conhecimento. Nota-se que para esses licenciandos, o professor é quem transfere o conhecimento e o aluno apenas recebe as informações transmitidas.

16 Os nomes de algumas disciplinas foram alterados para proteger a identidade do curso em questão.

\section{Referências}

ARROYO, M. Formar educadoras e educadores de jovens e adultos. In: SOARES, L. (org.). Formação de educadores de jovens e adultos. Belo Horizonte: Autêntica, 2006. p. 17-32.

ARROYO, M. Balanço da EJA: o que mudou nos modos de vida dos jovens-adultos populares? REVEJ@ - Revista de Educação de Jovens e Adultos, v. 1, p. 5-13, 2007.

BARBOSA, A. R. Atividades lúdicas no ensino de física: desafios e possibilidades para a EJA. 2018. Dissertação (Mestrado em Ensino de Física) - Universidade de Brasília, Brasília, 2018.

BECKER, F. Modelos pedagógicos e modelos epistemológicos. Educação e Realidade, Porto Alegre, v. 19, n.1, p. 89-96, 1994.

BRASIL. Decreto no 5.840, de 13 de julho de 2006. Institui o PROEJA e dá outras providências. Disponível em: https://www.planalto.gov.br/ccivil_03/_Ato2004-2006/2006/Decreto/D5840. htm. Acesso em: 1 jan. 2021.

BRASIL. Diretrizes Curriculares Nacionais Gerais da Educação Básica. Brasília: MEC, SEB, DICEI, 2013. Disponível em: http://portal.mec.gov.br/index.php?option=com_docman\&vie$\mathrm{w}=$ download\&alias=15548-d-c-n-educacao-basica-nova-pdf\&Itemid=30192. Acesso em: 1 jan. 2021.

BRASIL. Lei no 10.172, de 9 de Janeiro de 2001. Aprova o Plano Nacional de Educação e dá outras providências. Disponível em: http://portal.mec.gov.br/arquivos/pdf/L10172.pdf. Acesso em: 1 jan. 2021.

BRASIL. Lei no 13.005/2014, de 25 de Junho de 2014. Aprova o Plano Nacional de Educação - PNE e dá outras providências. Disponível em: http://www.planalto.gov.br/ccivil_03/_ato20112014/2014/lei/113005.htm. Acesso em: 1 jan. 2021. 
BRASIL. Lei no 9.394/96, de 20 de Dezembro de 1996. Estabelece as diretrizes e bases da educação nacional. Disponível em: http://www.planalto.gov.br/ccivil_03/leis/19394.htm. Acesso em: 1 jan. 2021.

BRASIL. Parecer CEB no 11/2000. Define as Diretrizes Curriculares Nacionais para a Educação de Jovens e Adultos. Disponível em: http://portal.mec.gov.br/cne/arquivos/pdf/PCB11_2000.pdf. Acesso em: 1 jan. 2021.

BRASIL. Parecer CEB no 6/2010. Reexame do Parecer CNE/CEB no 23/2008. Disponível em: http://portal.mec.gov.br/index.php?option=com_docman\&view=download\&alias=5061-parecercne-seb6-2010\&Itemid=30192. Acesso em: 1 jan. 2021.

BRASIL. Parecer CES no 1.304/2001. Define as Diretrizes Nacionais Curriculares para os Cursos de Física. Disponível em: http://portal.mec.gov.br/cne/arquivos/pdf/CES1304.pdf. Acesso em: 1 jan. 2021.

BRASIL. Resolução no 2 , de 1ㅜ de julho de 2015. Define as Diretrizes Curriculares Nacionais para a formação inicial em nível superior. Disponível em: http://portal.mec.gov.br/index.php?option=com_docman\&view=download\&alias=17719-res-cne-cp-002-03072015\&category_slug=julho-2015-pdf\&Itemid=30192. Acesso em: 1 jan. 2021.

BRAUN, V.; Clarke, V. Using thematic analysis in psychology. Qualitative Research in Psychology, v. 3, n. 2, p. 77-101, 2006.

BRUNEL, C. Jovens cada vez mais jovens na educação de jovens e adultos. 2. ed. Porto Alegre: Mediação, 2008.

FAJARDO, V. Ensino a distância: liberados para ensino médio, cursos EaD ainda são piores que presenciais. BBC News Brasil, São Paulo, 17 dez. 2018. Disponível em: https://www.bbc.com/ portuguese/brasil-46394590. Acesso em: 1 jan. 2021.

FREIRE, P. Pedagogia da autonomia: saberes necessários à prática educativa. 63 . ed. Rio de Janeiro/São Paulo: Paz e Terra, 2020.

GAMA, A. C. O ensino de física na EJA: uma proposta com foco na utilização de atividades experimentais demonstrativas - um exemplo no estudo da hidrostática. 2015. Dissertação (Mestrado em Ensino de Física) - Universidade Federal do Espírito Santo, Vitória, 2015.

GASKELL, G. Entrevistas individuais e grupais. In: BAUER, M. W.; GASKELL, G. (org.). Pesquisa qualitativa com texto, imagem e som: um manual. 9. ed. Petrópolis: Vozes, 2011. p. 64-89.

GIOVANETTI, M. A. G. C. A formação de educadores de EJA: o legado da educação popular. In: SOARES, L.; GIOVANETTI, M. A. G. C; GOMES, N. L. (org.). Diálogos na educação de jovens e adultos. Belo Horizonte: Autêntica, 2007. p. 243-254.

HADDAD, S.; DI PIERRO, M. C. Escolarização de jovens e adultos. Revista Brasileira de Educação, Rio de Janeiro, n. 14, p. 108-130, ago. 2000.

INSTITUTO NACIONAL DE ESTUDOS E PESQUISAS EDUCACIONAIS ANÍSIO TEIXEIRA (INEP). Sinopse estatística da educação básica 2018. Brasília, 2019. Disponível em: http:// portal.inep.gov.br/sinopses-estatisticas-da-educacao-basica. Acesso em: 1 jan. 2021.

JESUS, A. C. S.; NARDI, R. Imaginários de licenciandos em física sobre a educação de jovens e adultos e o ensino nessa modalidade. Ensaio Pesquisa em Educação em Ciências, Belo Horizonte, v. 18, n. 3, p. 51-71, dez. 2016. 
JESUS, A. C. S. Ensino de Física na Educação de Jovens e Adultos: um estudo de caso na formação inicial de professores. 2012. Dissertação (Mestrado em Educação para a Ciência) Universidade Estadual Paulista Júlio de Mesquita Filho, Bauru, 2012.

KOCH, L. L. Formação docente para a educação de jovens e adultos. In: LAFFIN, M. H. L. F. (org.). Educação de jovens, adultos e idosos na diversidade: processos de intervenção na realidade escolar e social. Florianópolis: Apoio, 2014. p. 39-55.

KRUMMENAUER, W. L.; WANNMACHER, C. M. D. Percepção dos professores de física na educação de jovens e adultos acerca do interesse discente pelas aulas. Revista Travessias, Cascavel, v. 10, n. 1, ed. 26, p. 353-367, 2016.

LABURÚ, C. E.; MAMPRIN, M. I. L. L.; SALVADEGO, W. N. C. Professor das ciências naturais e a prática de atividades experimentais no ensino médio: uma análise segundo Charlot. Londrina: Eduel, 2011.

LASRY, N.; MAZUR, E.; WATKINS, J. Peer instruction: From Harvard to the two-year college. American Journal of Physics, v. 76, n. 11, p. 1066-1069, nov. 2008.

LAMBACH, M.; MARQUES, C. A. Ensino de Química na Educação de Jovens e Adultos: relação entre estilos de pensamento e formação docente. Revista Investigações em Ensino de Ciências, Revista Investigações em Ensino de Ciências, Porto Alegre, v. 14, n. 2, p. 219-235, 2009.

LISE, L.; ANDREOLLA, R. O "novo" sujeito da educação de jovens e adultos: um diagnóstico necessário para uma intervenção pedagógica significativa. In: LAFFIN, M. H. L. F. (org.). Educação de jovens, adultos e idosos na diversidade: processos de intervenção na realidade escolar e social. Florianópolis: Apoio, 2014. p. 58-73.

LOCH, J. M. P. Planejamento e avaliação em EJA. In: LOCH, J. M. P. et al. EJA: planejamento, metodologias e avaliação. Porto Alegre: Mediação, 2009. p. 15-36.

MACHADO, M. M. Formação de professores para EJA: uma perspectiva de mudança. Revista Retratos da Escola, Brasília, v. 2, n. 2-3, p. 161-174, jan./dez. 2008.

MANZINI, E. J. A entrevista na pesquisa social. Didática, São Paulo, v. 26/27, p. 149-158, 1991.

MINISTÉRIO DA EDUCAÇÃO. Encceja. Brasília, 2018. Disponível em: http://portal.mec.gov. br/encceja. Acesso em: 5 abr. 2020.

MONTENEGRO, D. S. Formação inicial de professores de ciências (química e física) para a educação de jovens e adultos e o silenciamento dos cursos formadores. 2016. Dissertação (Mestrado em Ensino de Ciências e Matemática) - Universidade Estadual da Paraíba, Campina Grande, 2016.

MOREIRA, M. A. Aprendizagem significativa: a teoria e textos complementares. São Paulo: Editora Livraria da Física, 2011.

PINTO, A. V. Sete lições sobre educação de adultos. 16. ed. São Paulo: Cortez, 2010.

SILVA, L. C. Análise de material didático de física para EJA: do Telecurso ao PNLD-EJA. 2017. Dissertação (Mestrado em Ensino de Física) - Pontifícia Universidade Católica de Minas Gerais, Belo Horizonte, 2017.

SILVA, Leonardo Cristiano da. Análise de material didático de física para EJA: do Telecurso ao PNLD EJA. 2017. Dissertação (Mestrado em Ensino de Física) Pontifícia Universidade Católica de Minas Gerais, Belo Horizonte, 2017. 
SILVEIRA, F. L.; MOREIRA, M. A.; AXT, R. Habilidad en preguntas conceptuales y en resolución de problemas de Física. Enseñanza de las Ciencias, v. 10, n. 1, p. 58-62, 1992.

SOARES, L. Educação de jovens e adultos. Rio de Janeiro: DP\&A, 2002.

SOUZA, M. A. Educação de jovens e adultos. Curitiba: Editora InterSaberes, 2012.

VENTURA, J.; BOMFIM, M. I. Formação de professores e educação de jovens e adultos: o formal e o real nas licenciaturas. Educação em Revista, Belo Horizonte, v. 31, n. 2, p. 211-227, jun. 2015. 